\title{
Creativity in Crisis: a Journey into YouTube
}

\section{Tomoaki D. Imamichi ${ }^{1}$ (iD}

Received: 17 July 2020 / Revised: 13 February 2021 / Accepted: 17 February 2021 /

Published online: 10 March 2021

(c) The Author(s), under exclusive licence to Springer Nature Switzerland AG part of Springer Nature 2021

\begin{abstract}
Crisis comes with dangers and opportunities. Necessity is the mother of invention. This article explores creativity in crisis in the academic context from my personal perspective. This pandemic and stay-at-home order necessitates academic activities, teaching, in particular, to transition to a remote format. The loss of physical space, in-person contact, and taken-for-granted everyday activities comes with major concerns and requires major adjustment. The stay-at-home order necessitates rethinking teaching and learning-not just the delivery of content but the content itself, the practice of academia in general. Much of it involves increased usage of familiar and unfamiliar technologies, experimenting with different formats, and brings relevance to the course content to these circumstances. In short, the current situation requires reexamining one's relationship with technologies and some degree of creativity in a broad sense. This creativity can also lead one into new and unexpected realms - such as the increased reliance of YouTube, not as a user, but as a creator of videos. This article will involve a selection of diverse short video clips for educational purposes that emerged out of this crisis situation.
\end{abstract}

Keywords Crisis $\cdot$ Creativity $\cdot$ YouTube $\cdot$ Pedagogy $\cdot$ Academia $\cdot$ Distance learning

\section{Crisis: Dangers and Opportunities}

Crisis in Japanese is written with the Chinese characters 危機 (kiki), which is comprised of two characters. The first character 危 $(k i)$ is associated with 危険 (kiken) which means danger and the second character 機 $(k i)$ with 機会 (kikai) which means opportunity. This seems to indicate that with crisis come dangers and opportunities, and that there are some possibilities for transformations, but transformations into what one may ask. This article is comprised of two parts. In the first part, I will be musing about the dangers and general concerns, and in the second part, I will be focusing on opportunities and my personal journey into YouTube. Both parts deal with my ambivalent relationship to technology.

With many crises, some of the initial thoughts that come to mind are the dangers of the consolidation of power, the exploitations of people's vulnerabilities, and "opportunities"

Tomoaki D. Imamichi

Imamichi@gmail.com

1 City University of New York, LaGuardia Community College, Graduate Center, NY, New York, USA 
for public-private partnerships, which often lead to an amplification of social and environmental injustices, when public funds get diverted to support corporate interests. The term disaster capitalism applies, as often crisis situations are used as opportunities for profit making, when there is a sudden surge in demand of particular goods and services. Crisis situations are also used for corporations whose profits are at risks as rationales for government aid.

The term disaster fascism applies, as crisis situations are used as opportunities to for governments to implement measures to increase their surveillance and control over their citizens. It reminds me of the post 9/11 climate of the USA and the post 3/11 (Fukushima Nuclear Disaster in 2011) climate of Japan where politicians pushed for more national security and public order measures at the expense of civil liberties.

Surveillance and control are facilitated by technology. Even before the COVID-19 and the stay-at-home order much of everyday transactions heavily relied on technologies that have put privacy at stake (Zuboff, 2019). This only has been exasperated with ever more technological dependency in order to compensate for the lost mobility, that necessitates remote working, distance learning, and the surge in online activities for ordering basic necessities. This then leads to even more surveillance and more discipline, where we might think of Foucault (1975), how the very idea of being watched impacts behavior. This current crisis seems to set the stage for a transformation into an ever more technocratic dystopia.

\section{Part I: Dangers: the Ever More Technocratic Dystopia}

The ever more technocratic dystopia speaks to different identities one may have. For myself, they range from a concerned citizen, a worker and educator, an academic, and an environmental psychologist. These identities have become evermore embedded in technologies that have led to the phenomenon of the saturated self (Gergen, 1991), the dramatic expansion of relation already conceptualized three decades ago, when the Internet was still in its infancy, and many of the take-for-granted current technologies (e.g., wi-fi, smartphones) and technology contingent services (e.g., Amazon, Google, Wikipedia, Facebook, YouTube, Twitter, and more recently Zoom) not yet available. These technologies have become part of our selves. They are extensions or our selves; they are intertwined in almost every aspect of our everyday lives. People relationships with technology are also constantly evolving and take an ever more important aspect in the study of everyday lives (Chimirri $\&$ Schraube, 2019). In a sense, they may empower us, but they have power over us as well.

\section{As a Concerned Citizen}

As a concerned citizen, I feel surveilled and "remote controlled," an increased sense of computer and Internet-dependency. I also experience a sense of technological vulnerability-if for one reason or other my computer or Internet connection is disrupted. The next virus may be a computer virus. With the increase of technocracy may be a loss of public spaces, which are important conditions for democracy. Being in public spaces allows people to see things for themselves, and not only what is mediated through mass or social media. As much as some of the recent political movements involved social media-technology, nevertheless, they needed a physical space, a public space to materialize. Revolutions do not happen just on cyberspace (via uploaded videos on Facebook, Twitter). While social 
media enables the spreading of information (and misinformation), the information needs to be based on events that happened in physical spaces, and further a call to claim public spaces. There is strength in numbers; to reach a threshold is important to gain national and international attention, and to overwhelm government forces, who may show restraint in light of potentially devastating publicity, and for practical reasons of handling the sheer number of potential arrests and detention. And yet, it is not only the public squares themselves but also indoor public gathering places, often situated near pivotal outdoor places, that allow for organization, staging, and retreat areas, such as Churches in case of the Peaceful Revolution in East Germany that lead to the Fall of the Berlin Wall, which symbolized the Iron Curtain, and a pivotal moment leading to the end of the Cold War, or Mosques in the case of the Arab Spring (Rabbat, 2012).

Despite the COVID crisis, people in the USA were taking to the street to engage in the Black Lives Matter Movement and protest Police violence. In a sense life was getting "back to normal," epitomized by the murder of a Black man at the hands (or knee) of the police that was captured on video and shared on social media. But perhaps it was also because of the current COVID crisis that people are taking to the streets. They have been tired of the lockdown, and at the same time concerned that life would get "back to normal" in the oppressive sense and are eager for action. And that action cannot merely be confined to the virtual - it takes the physical, public places.

At the same time, there is another kind of people that are taking to the streets, those who believe in their right to ignore medical authorities and public health advisories, whether it stems from their sense of entitlement to contract COVID and spread it to others, or their right to live in an alternative reality in which COVID does not really exist, also made possible through social media going out of control.

To some extent, it is the role of education that cultivate a consciousness that can lead to a better society, and at the same time help develop a degree of critical thinking and scientific literacy to decipher government and social media messages that allows to make informed decisions.

\section{As a Worker and Educator}

As a worker and educator, I find myself in conditions of remote working and distance learning, where there is much technological integration, but at the same time a sense of existential alienation and disconnection. One of the rewards and satisfaction of working and learning may be the interaction with one colleague and peers, and the informal, causal, and spontaneous encounters that are eliminated. As an instructor some of the most interesting conversations and much of learning may happen before and after class, or during breaks, at times by overhearing students speak to each other on current events and pressing issues that can connect to course content. Speaking of overhearing, with the digital format, the posting of course content, and the recording of lectures, all correspondence is subjected to a digital trace. Hence, any instructors may be extra mindful, disciplined, and self-censoring (Foucault, 1975) of what they spell out on their digital platform with the potential surveillance.

Another aspect, particularly in the early stages of transitioning was the amount of extra work involved in moving the classes online, where there was a sense of doing a lot more work, while getting a lot less done. Even with lowered expectation of "emergency remote teaching" and not "online learning" (Hodges et al., 2020), it seemed that on the instructor side there was much input, and much less output. The temptation to reach out for an easy 
technological fix may have never been greater, even at the risk of giving up one's academic "creativity" and integrity, a dystopia foreshadowed well before the crisis (Carr, 2010; Oppenheimer, 2004). Textbook companies are seizing this opportunity by aggressively marketing their prepackaged course materials with plenty of online content from automated "edutaining" activities and self-grading instant feedback exams that almost make the instructor obsolete reducing them to web administrators and tech support for students. This phenomenon may be used justify prohibitively high textbook prices and abysmally low adjunct instructor wages. Academic freedom is reduced to choosing course packages and modules, and even that should not be taken for granted, as some departments require instructors to work with a specific course package and modules. As I am uploading more and more of my course content on online platforms, am I unknowingly contributing to my own demise? Do I need to compete with the course packages and modules, and will I be judged against them. Am I enriching the educational companies with my and my students' uploaded content?

Concerns about the Internet include how plagiarism would become increasingly easy. But this was overly optimistic considering the deteriorating content of what is copied and pasted, because students seem to no longer able to distinguish between material worthy of stealing. But now they also have the opportunity to turn to online services that write generic papers for them in response to generic course content. Concerns about students no longer engaging in the course content could be extended into instructors who no longer have to engage in the course content, when content is generated and graded by course packages, or possibly outsourced to online services (that not only generate generic papers for students, but grade the generic papers for instructors).

\section{As an Academic}

As an academic issues such as "computer and internet privilege" come to mind. This privilege has several connotations. One is the privilege that emerges with the better computer and Internet access. Not everyone has access to the newest technologies and best Internet access. One of my concerns in participating in the virtual conference was an unstable Internet connection, which I have frequently encountered throughout virtual meetings and live lectures that compelled me to upgrade my Internet Service and purchase a signal booster. In the context of remote working and distance learning, households may be required to share computers and Internet access, which then limits their opportunities to fully participate.

Another privilege is for those who may be more versed with the use of various technologies. Ironically, I encountered some technical difficulties during my presentation, which was in part due to my lack of fluency in screen sharing, but to some degree the counterintuitiveness and lack of feedback of the particular technology.

Finally, there is the privileging of the mediated over the direct, the virtual over the physical, and the implication it may have on "being" and "doing."

\section{As an Environmental Psychologist}

As an environmental psychologist, there are concerns about an ever more perceived obsolescence of physical space and in-person interaction. Depending on the field one is in there are various important physical spaces such as the studio, the lab, the classroom, the field - all of these provide tangible opportunities for the "hand-on," the experiential, and the accidental, which all are important conditions for creativity. But it is not only these 
tangible places and settings that drive and fuel creativity. Many the taken-for-granted everyday activities and experiences have been impacted by restrictions of movement, travel, and physical contact that are so often are sources for inspiration. Particularly, city dwellers that had access diversity and cultural experiences that so often characterize city living and who compensate small apartments with neighborhoods as extensions of their living rooms are now being deprived.

\section{Part li: Opportunities: Any Good that can Come Out of This?}

Despite the concerns that come with the crisis, there is potential good that could come out of this, ranging from ecological, social, and psychological aspects.

\section{Ecological}

There is some ecological relief, the lockdown situation has been beneficial for environment, and many of the measures should have been taken a long time ago, in slightly different ways of course. But the reduced production and unessential travel are drastically reducing the ecological footprint and are leading to visible changes in the environment ranging from water and air quality. Thus, these would have some considerable benefits for people with respiratory issues, often triggered by poor air quality, and for future generations. These could put a dent in the graphs depicting the era of acceleration (Steffen et al., 2015).

\section{Social}

This may be an opportunity for people to reconsider what they understand under essential travel, and essential goods and services, and possibly reconsider their priorities and lifestyle. Thus, this disruption can serve as an impetus for radical change. Sometimes disasters can lead to community building (Solnit, 2009).

Disruptions can serve as an impetus to finally address larger pressing issues ranging from capitalism (Klein, 2015) to education (Worldwatch Institute, 2017).

\section{Psychological (No FOMO)}

From a psychological perspective in some respects spending more time at home can also have some considerable benefits, depending, of course, on one's living situation.

Particularly, if when one has the privilege or "environmental capital" to have access to a basement, or the woods, and can draw on past urban experiences-direct social and cultural encounters that one may be deprived of in a lockdown situation. The basement and the woods may be great places to think and get ideas, but there meaningfulness to a great extent hinges on past social and cultural encounters that one can draw from and reflect upon. As much as a person likes to withdraw sometimes for some "alone time" in the basement or garage, it does not necessarily mean the person likes to be alone all the time. As much as a person likes to spend time in woods, it does not necessarily mean spending all the time in woods. But it is certainly a good opportunity to spent some guiltless and worryfree alone time; there is no fear of missing out, when most events are cancelled, and one is being asked to stay at home: One can be "a hero" and do one's part by just staying home. 
For an introvert, this may be a blessing in disguise. And it is during this alone time and staying at home that could be a time used for a break, an incubation period, which has been shown to improve problem-solving and creativity (Sio \& Ormerod, 2009).

\section{Calls for Creativity}

There are calls for creativity, calls for adjustment on different levels, because the lockdown requires major adjustments in our everyday lives. But the question becomes adjustment to what? Is it going to be to the "new normal" within the old status quo?

When it comes to creativity, one can also consider creative resistance-ways in which to limit one's support to the major corporation that are benefiting and further profiting from the crisis at the expense of other vulnerabilities, ways to limit dependency on certain teaching technologies and platforms that may infringe on people's privacy, and insuring that the crisis situation will not be exploited to make temporary measures become permanent.

When it comes to creativity, one can also consider transformations, in which this crisis situation can be used on personal level to reinvent oneself-through possibly spending more time in the basement or in the woods and on a communal and social level to reconsider the "old normal" and contemplate that there are many aspect one would rather not "go back to" but help shape "a new normal".

This ties in with the Psychology of Global Crisis Virtual Conference held in May 2020. The conference itself seized the crisis. Given the circumstances where several scholars where on lockdown and had nowhere to go, being faced with a situation highly relevant to their academic interest and personal lives, many seemed eager to participate, and the conference managed to assemble an impressive list of speakers. Furthermore, in its call for contributions, it emphasized how the format allowed handling "a large variety of contribution" and that actively encouraged "creative and experimental formats " which inspired this writing, which is based on the conference contribution. Taking this call for contribution rather literally, I felt called upon to seize this opportunity to contribute with a presentation on a series of select short video that were recently made (Feeling ok?, Together Alone, Personality and Crisis, Mono-no-aware, Conversation between a YouTuber and an Academic) in transition to "distance learning" for different psychology classes- ranging from General Psychology, Social Psychology, and Environmental Psychology.

\section{Maintaining a Presence}

One of the main impetus was maintain a presence and attempt of "being-there" without really "being there." In a way, to create a presence beyond the classroom, as the classroom in the traditional sense no longer existed. Furthermore, at the time, there were many uncertainties about the online platforms of live-lectures, in terms of technologies as well as the use of these technologies. This may be considered part of "adjustment." However, there was also a transformative part in the attempts to maintain a presence, because my presence was no longer bound to the physical space of the assigned classroom and meeting times. My virtual presence allowed me to be present different spaces and different times, and in a certain sense I could repeat myself or rather I could be repeated, multiple times without getting tired. There is an interesting juxtaposition, while being confined with the stay-at-home order, it allowed me to be more "out-there" even beyond the classroom in a literal sense, because some of my videos, based on the number of views, well exceeded the 
students in the classroom. The potential impact that could be made went far beyond the classroom and the current class. A pandemic may bring thoughts about one's mortality, and in a way, the videos would be a record and a guarantee for some form of future presence. An given that most of the videos are a result of a well rehearsed, and the best version out of multiple takes, I can assure myself that all these kinds of "prerecorded virtual presence" may be better versions of myself. The "recorded self" may be better than my "live self." At the same time, I must consider to "live with myself" with a recording that may have seem like a good idea at the time, but perhaps not so much at a later time.

\section{Practice}

Despite fears of a technocratic dystopia, one can also muse about the wonders of technology how they have enabled the practice of making and broadcasting such videos. If such pandemic had stricken a decade earlier, as a late adopter of technology, I would have been a lot less prepared, as the laptop at the time would have not had the now almost takenfor-granted built-in user-friendly features, of which I only recently made fuller use. From a historical perspective, it is interesting to note that we can do more with fewer things (Trentmann, 2016). Not so long ago, there was a time when making a video involved several separate technological devices ranging from video cameras, tapes, to editing equipment, which placed the hurdle of making a video much higher, ranging from the access to the devices to the knowledge and skills in operating the devices. Procedures have become much simplified and video quality much improved. Furthermore, making a video is one thing, but sharing it is another, which with the advancement of the Internet and platforms such as YouTube that technically allows for easy access to a wide audience.

Encouraged by the possibilities of a one-man-operation via a laptop and Internet access, the impetus was to practice. Practice can be understood in two ways. In German, there are two words for it- $\ddot{U} b e n$ and Ausüben. Üben refers to practice in the sense of learning and trying, and Ausüben refers to practice in the sense of applying. In this context, both kinds of practice apply: practice in the sense of learning and trying, and applying something else, something else from an ordinary classroom experience and becoming "someone else." Rather than trying replicate the physical class in a virtual format, the attempt was made to do something unique (undoable in the physical class) in the virtual format. The making of short videos for various courses would not have occurred, had it not been for the crisis situation. The making of short videos provided an opportunity for the instructor to rethink some of the course material, if not the field of psychology itself. This may be considered part of "transformation."

\section{Transformations?}

To some degree the sentiment of transformation through self-recording and self-observation expressed in the video Feeling ok? (https://youtu.be/jge8OQpt8pc), where I am commenting on myself "spending much time in the basement, talking to myself, talking to the computer, making videos that hardly anybody watches." But I am also trying to justify this behavior as not only part of an adjustment process to remote working and distance learning but also a potential transformation process, which precisely may be through talking to oneself and observing oneself. This video was introduced in the General Psychology class under the topic of Psychological Disorders and Treatments. One of the questions to 
be raised was what kind of behaviors may raise suspicion, and how do contextual and situational factors play a role in particular behaviors.

The video Together Alone (https://youtu.be/hve8aZnEVVU) picks up on the theme of "feeling ok" and being in the basement, but rather in form of a monologue, it is in a form of a song, accompanied by guitar playing. This time reflecting on spending much time being online, connected, but out of touch, and the stress associated with digital overload. This is also a reference to Turkle (2011), who expressed concerns about the overreliance on technology, which takes on new relevance with COVID-19.

The video Personality and Crisis (https://youtu.be/G_-lhVPBWiI) follows a more traditional format of an instructor in front of a blackboard and trying to lecture about personality traits, specifically the Five Factor Model, the widely used and researched personality model. But rather than a general lecture, the video is making specific reference these personality factors in the context of a crisis, specifically a pandemic, illustrating how the different personality factors have an impact on the stay at home order. The video ends with the association that people with higher on the neuroticism dimension are at higher risk for depression and anxiety, but that of course any crisis situation such as a pandemic can lead to stress - but that when it comes to stress that there are plenty of other videos to watch-making references to earlier videos for past classes on emotion, stress, and coping, with short snippets that mention the Two-Factor (Schachter-Singer) Theory of Emotion, Meaning Making Coping, Restorative Environments, and Bubble-Wrap Popping, all videos that fall under the "Feeling stressed Series": The Two-Factor Theory and Meaning Making Coping were videos that were presented in past General Psychology classes, while Restorative Environments was a video for the Environmental Psychology course, and Bubble-Warp Popping a video that was not presented to any class - and yet had relevance to the topic and reference to a study (Dillon, 1992) that showed the stress relieving properties of bubble-wrap popping.

The Mono-no-aware video (https://youtu.be/nSr4t8Cvpu4) takes the viewer outside in front a flowering Magnolia tree in windy and rainy weather, capturing a unique moment to explain the Japanese concept of mono no aware (物の哀れ) - the pathos of things, the aesthetic of impermanence. This video was for the context an Environmental Psychology class exploring environmental attitudes and ways to not just accept but embrace, cherish, and contemplate various environmental phenomena as reflection on life itself. Most magnolia trees may be captured on video in full bloom in fair weather, which was also done for the Restorative Environment video, rather when they are past their peak in wind and rain. However, it is this very sentiment of the feeling a sense of sadness, loss, and the passage of time, in which there is a sense of beauty and being present. But no longwinded explanation captured that sentiment better than an actual footage of the flowers battered by the wind and the rain. It would be a challenge to arrange a field trip that could capture such a moment as well, to have the seasonal and weather convergence of flowers past their peak in the in the wind and the rain. An additional blessing was that while I was standing amidst the flower branches, the wind picked up, so that the flowers were hitting me in the face, which added to the pathos and a slight comic element. It was a unique moment and a spontaneously shot video, on a day that under ordinary circumstances would have been spent in a windowless office or classroom. I would have completely missed that moment, let alone the opportunity to make this video.

The Conversations between a YouTuber and an Academic video (https://youtu.be/ r04udZtTDkA) shows me engaged in a "dialogue" of my dual roles of a "YouTuber and an "Academic" engaging in psychological topics. This sort of role-playing particularly the academic, which includes dressing the part with a jacket, and staging the part via a book stack, 
and multiple takes, affords a presentation that cannot be replicated in the classroom setting. It further explores the tension of providing content in different context and criteria-the context of entertainment conscious YouTube and educational conscious Academia. This video made in mind on the topic of stereotypes and how at times we ourselves are trying to live up or avoid certain stereotype associated with our multiple social identities and roles.

\section{What Does It Take for 2-min Video?}

While some degree of role-playing and staging occurs within the regular classroom context, videos provide opportunities for the instructor beyond the regular classroom context. Videos provide opportunities for multiple takes to get it right. Thus, even a seemingly short 2-min video may be the result of some considerable preparation in terms of scripting a monologue. Because the video is short, I want to choose my words wisely, almost as if trying to compose a haiku or a short poem. There is also the need to set the stage, even if it means giving it an empty look, which means moving distracting objects out of the way, or assembling objects to deliberately-casually placed, for example, the placement of books to represent the "academic" in the conversation between an YouTuber and an academic. It also means dressing the part. There is a considerable effort in self-presentation (c.f. Goffman, 1956), which ranges from what one says how, to how one looks, and the environment, particularly given the potential that "the show" may be potentially viewed by several people and be lasting record, so I want to get it right. Fortunately, there are several opportunities to get it right. There is the possibility for multiple takes, to record and review, and then upon review, rescript and rerecord. Scripting is one thing. Once I act out the script and review the recording, I sometimes discover that some seemingly great ideas were not so great after all. Sometimes new ideas emerge in the process. And some of these ideas may not only pertain to the content of the script itself. I may use the same line, but I may deliver them differently. This is a creative process in the sense of "acting with iron" that to some extent one enters with a general idea and plan, but is flexible to yield to some to what is emerging in the specific context (Keller \& Keller, 1993). The Mono no aware video rather spontaneously emerged from a convergence of fortunate circumstances of teaching an Environmental Psychology class exploring environmental attitudes, and a magnolia tree in full bloom and windy rain, as well as the flower branches half-planned half-accidentally hitting the face, adding a tragic-comic quality to the video, which may give the video a wider appeal, as well.

Some videos involve editing, such the Personality and Crisis video, and most of the video included in the "Feeling Stressed Series" that all start out with the same footage of a question "Are you feeling stressed? Perhaps you can try..." On the one hand, each of the videos is standalone, yet they can also be considered part of a series, as they address the same question with different approaches.

Some video involve closed captioning, particularly if they are assigned for class, as part of making the video more accessible, and as part of reinforcing learning by hearing and reading the content. This may also support English language learners that make up a significant portion of the student population. In addition to the pause and replay features of a video, the close captioning can be of additional help when the spoken words are spelled out. Some videos may have also appeal for an international and multilingual audience, particularly videos that address cultural concepts- such as mono-no-aware. The creating of subtitles in Japanese and German forces an engagement with the content 
in different languages, and the challenges of translation, which inspired another videoConversations between a Japanese and a German (https://youtu.be/ciNqLdhIP0A).

But rather than pondering how long a 2-min video take, the more important question may be, how long does a 2-min video last. In terms of memorability, they may last longer than a lecture. Furthermore, the time invested in the video may pay off at a later time when it is available for viewing, when I can be virtually present.

\section{What Could a 2-min Video Do?}

As much as the videos are intended for the students in my class and potentially a wider audience, who may be interested in the topics, there are additional things that the videos can do.

There are opportunities to rethink the material and engage with the material from different perspectives (as a YouTuber) and potentially connect to students in more ways. It also added another layer of excitement in engaging with the material, particularly the thought that the world is full of opportunities to turn everyday environments and experiences into a short video that could relate to a psychological concept and could be used as a teachable moment to be shared. The making and sharing of one video can inspire new videos. All of this can be seen as a work in progress, which was also the way I have approached the video making and the conference presentation. Niklas Chimirri (in the discussion portion of my presentation at the conference) also suggested that creativity and video making could be something to be encouraged in students - to make a 2-min video or less about a psychological concept or something they feel would be worth sharing with the wider world. This will be implemented in upcoming semesters and may be subject to a future article. The encouragement of students in creativity and video making sure would engage students with the material in new ways, where they can practice (Üben and Ausüben) psychology and other skills, adding a layer of excitement to the class, for themselves, their classmates, and their instructor. They, too, may find ways to interpret and own the material, express themselves, shed new lights on it, possibly expanding the concept and contribute to the field of psychology by making interesting for themselves and others, and reaching a wider audience. The wider audience may be reached by making the material accessible by capturing and demystifying a concept in a 2-min video, put in visuals and a language that speaks to potentially different audiences. The wider audience may be reached if the material accessible is publicly available on YouTube, which will make it more likely to be accessed, perhaps even accidentally. In such instances that video may be more likely to be accessed than a paper, an academic paper in particular. However, through my very practice of the engagement with YouTube (by uploading content and recommending them), inadvertently, I am supporting YouTube and the parent company Google-the very company that is cause of concern in terms of privacy issues, surveillance and control.

Some other cause of concern may be if concepts get overly watered down, or even misrepresented, particularly when publicized. But this seems to be a tolerable risk, particularly considering the material that is already out-there, and there may be opportunities for commentary and discussions in the comment section. It may also be worth considering that overly dry academic papers are not necessarily packed with content either, though they are legitimized with academic credentials, backed by institutional support, and blessed by peer-reviews. 


\section{Conclusions}

Speaking of crisis, the field of Psychology has also had its history of crisis, struggling with its definition as epitomized in the 1968 Encyclopedia Britannica entry that retraces the shifts from the late nineteenth century to the midtwentieth century: "It has been said, psychology has lost its soul, mind, then consciousness, and now it is having trouble with behavior." Despite regaining portions of the mind with the cognitive revolution, much of psychology seems still stuck desperately attempting to emulate the physical sciences in order to legitimate itself as a Science (with a capital S), and by doing so ending up "objectifying" and "neutralizing" humans and experiences by taking the life out of them, reducing them to hypothesis testable variables, and also have been referred to sarcastically as the magic of modern psychology "turning wine into water." This concern has been taken up by critical psychology (Maier, 1991) and another telling commentary by Kvale (1992) that a visit to the Psychology section in a college bookstore evokes a sense of boredom, whose edited book interesting and creative chapters that showed possibilities of different kind of psychology (also pursued in Slife et al., 2005). A different kind of psychology could include an incorporation of different kinds of technologies, whether it comes to theorizing, researching, and practicing in a critical and creative manner to enrich the field of psychology and beyond. To some extent, I see my engagement with YouTube a step towards that direction.

It was the crisis that pushed me to engage in technologies and approaches that otherwise I would have not engaged in. They gave me a glimpse into the potential of becoming a better educator and academic, and possibly forging a new identity as a "multimedia artist." What first started out with minimalist approach due to the limited knowledge of the technologies, gradually upgraded to more complex videos that include more editing techniques and "special effects" that also lend themselves to new ideas. The limitations from this pandemic made me focus on the few things that I could control. The stay-at-home order made me stay at home. This meant significant time not spent commuting and not travelling, and significant more time spent at home. Some of that time allowed for guilt-free exploration of the features and possibilities on my laptop. I could tell myself that this is part of my professional development- to enhance my digital competency and my pedagogy. To some extent this has served me well when instructors were asked to make a short video to encourage enrollment: Here in my garage-college (https://youtu.be/OKWCHBFEsI8), and then a short video about their courses, where my recently acquired skills in editing came in handy: Introduction to Environmental Psychology (https://youtu.be/E_pfFjd13T0).

Once I began to engage with the technology, I became more familiar with it allowing me to do more with it, particularly because of the ease in which a video can be made on one's laptop — an all-in-one device ranging from video camera to editor, and also a music maker, with intuitive and user-friendly features, as I have tried to illustrate with a video that celebrates numerous available technological features that came with the now ubiquitous laptop: Here in my garage with a laptop (https://youtu.be/xu8OOPs_bI), which I consider to be an upgrade compared with my previous music video (Together Alone) that did not involve multiple cuts, and multiple tracks (drums, bass, synthesizers) all created on the laptop. Perhaps I got too carried away and spent too much time on something peripheral, and yet there was something deeply satisfying. It was this context, the stay-at-home order and a laptop, that helped me emerge with more creativity. 


\section{References}

Carr, N. (2010). The shallows: What the Internet is doing to our brains. W. W. Norton.

Chimirri, N. A., Schraube, E. (2019). Rethinking psychology of technology for future society from within morethan-human everyday life. In K. O’Doherty, L. Osbeck, E. Schraube, J. Yen (Eds.), Psychological studies of science and technology. Palgrave 49-76.

Dillon, K. M. (1992). Popping sealed air-capsules to reduce stress. Psychological Reports, 71(1), 243-246. https://doi.org/10.2466/pr0.1992.71.1.243.

Gergen, K. (1991). The saturated self. Basic Books.

Goffman, E. (1956). The presentation of self in everyday life. Double Day.

Hodges, C., Moore, S., Lockee, B., Trust, T., \& Bond, A. (2020). The difference between emergency remote teaching and online learning. Educause Review, Retrieved from: https://er.educause.edu/articles/ 2020/3/the-difference-between-emergency-remote-teaching-and-online-learning

Foucault, M. (1975). Surveiller et punir. Gallimard.

Kvale, S. (1992). Psychology and postmodernism. Sage.

Keller, C., Keller, J. D. (1993). Thinking and acting with iron. In S. Cahiklin \& J. Slave (Eds.), Understanding practice, perspectives on activity and context. Cambridge University Press. 125-143.

Klein, N. (2015). This changes everything: Capitalism vs the climate. Simon \& Schuster.

Maiers, W. (1991). Critical psychology: Historical background and task. In C. Tolman (Ed.), Critical psychology: Contributions to an historical science of the subject. Cambridge, UK: Cambridge University.

Oppenheimer, T. (2004). The flickering mind: Saving education from the false promise of technology. Random House.

Rabbat, N. (2012). The Arab revolution takes back the public space. Critical Inquiry, 39(1), 198-208.

Sio, U. N., \& Ormerod, T. C. (2009). Does incubation enhance problem solving? A meta-analytic review. Psychological bulletin, 135(1), 94-120.

Slife, B., Reber, J., Richardson, F. (Eds.).(2005). Critical thinking about psychology: Hidden assumptions and plausible alternatives. American Psychological Association.

Solnit, R. (2009). A paradise built in hell: Extraordinary communities that arise in disaster. Penguin.

Steffen, W., Broadgate, W., Deutsch, L., Gaffney, O., \& Ludwig, C. (2015). The trajectory of the Anthropocene: The Great Acceleration. The Anthropocene Review, 2(1), 81-98.

Trentmann, F. (2016). The Empire of things: How we became a world of consumers, from the Fifteenth Century to the Twenty-First. Allen Lane.

Turkle, S. (2011). Together alone. Basic Books.

Worldwatch Institute. (2017). Earth Ed: Rethinking education on a changing planet. Island Press.

Zuboff, S. (2019). The age of surveillance capitalism. Public Affairs.

Publisher's Note Springer Nature remains neutral with regard to jurisdictional claims in published maps and institutional affiliations. 